\title{
Leishmaniose em cães domésticos: aspectos epidemiológicos
}

\author{
Leishmaniasis in domestic dogs: \\ epidemiological aspects
}

\author{
1 Instituto Oswaldo Cruz, \\ Fundação Oswaldo Cruz, \\ Rio de Janeiro, Brasil. \\ 2 Centro de Ciências \\ da Saúde, Universidade \\ Federal do Rio de Janeiro, \\ Rio de Janeiro, Brasil. \\ 3 Escola Nacional de Saúde \\ Pública, Fundação Oswaldo \\ Cruz, Rio de Janeiro, Brasil. \\ Correspondência \\ A. V. M. Silva \\ Laboratório de \\ Imunomodulação, \\ Departamento de \\ Protozoologia, \\ Instituto Oswaldo Cruz, \\ Fundação Oswaldo Cruz. \\ Av. Brasil 4365, Pavilhão \\ Carlos Chagas, 3o andar, \\ Rio de Janeiro, \\ 21045-900, Brasil. \\ albavmsilva@click21.com.br
}

\begin{abstract}
In Barra de Guaratiba, an endemic area for American visceral leishmaniasis (AVL) in Rio de Janeiro, Brazil, control campaigns were unable to reduce canine infection rates. This difficulty prompted an in-depth study of dogs as a reservoir for Leishmania chagasi in the peri-urban environment through clinical and serological follow-up using the immunofluorescence and Western blot techniques. Recognition of $29 \mathrm{kDa}$ and $32 \mathrm{kDa}$ peptides by sera from dogs with proven L. chagasi infection was observed. Furthermore, only sera from symptomatic dogs recognized the 68.5kDa antigen, so the latter should be considered a parameter for culling dogs from endemic areas. The WB technique proved to be more sensitive than IFA, since the 29 and $32 \mathrm{kDa}$ peptide fractions were even recognized by sera from AVL seronegative dogs up to 8 months before IFA seroconversion. Proximity to wooded areas was an important risk factor for L. chagasi infection in dogs, possibly due to the presence of wild reservoirs.
\end{abstract}

Visceral Leishmaniasis; Dogs; Fluorescent Antibody Technique; Western Blot
Alba Valéria Machado da Silva 1

Adelzon Assis de Paula ${ }^{2}$

Maria Alice Airosa Cabrera 3

João Carlos Araújo Carreira 1

\section{Introdução}

Desde 1908, quando relataram pela primeira vez na Tunísia a presença de formas amastigotas em canídeos domésticos 1 e no Brasil 2 quando observaram intenso parasitismo cutâneo em cães e raposas do Ceará, os cães têm sido considerados como importantes reservatórios no ciclo doméstico da leishmaniose visceral (LV).

Por causa da importância do cão como reservatório da LV americana (LVA), a Fundação Nacional de Saúde (FUNASA) adota no Brasil como medida de controle em áreas endêmicas, a eliminação destes animais quando são soropositivos para Leishmania chagasi. Essa estratégia entretanto, tem apresentado resultados controversos, demonstrando que muitos as pectos relacionados ao papel do cão na epidemiologia da LVA ainda são desconhecidos, sugerindo a necessidade de uma reformulação das medidas empregadas para o seu controle 3 .

Um aspecto importante, que provavelmente está associado com o insucesso do controle da LVA, refere-se aos critérios usados para a seleção dos cães a serem eliminados, que se baseia no diagnóstico por técnicas sorológicas (IFA e ELISA). Essas metodologias apresentam baixas sensibilidade e especificidade, acarretando taxas de infecções subestimadas e conseqüentemente permitindo a manutenção de animais infectados nas áreas endêmicas 3 . 
Estudos recentes descrevem a técnica de Western blot (WB) como a mais sensível e precoce, quando comparado com o IFA e ELISA, sugerindo a possibilidade da sua utilização como preditora da doença e do parasitismo no cão 4 .

Visando fazer um estudo utilizando as técnicas de WB e IFA, selecionamos a região de Barra de Guaratiba, área endêmica para LVA, onde têm sido relatados nos últimos anos, tanto casos humanos quanto caninos, sendo que a soroprevalência canina ainda permanece alta, a despeito das medidas adotadas para o controle da doença. Essas condições possibilitaram o desenvolvimento do presente trabalho cujos objetivos foram, aprofundar o conhecimento do papel do cão como reservatório da LV e utilizando-se as técnicas de IFA e WB, tentar correlacionar status clínico e infectividade para o flebótomo com os títulos sorológicos do IFA e frações antigênicas do WB, para ver se é possível identificar em uma população canina, os que estão sendo fonte de infecção.

\section{Material e métodos}

\section{Área de estudo}

Barra de Guaratiba é uma área periurbana, situada no litoral da cidade do Rio de Janeiro. $\mathrm{O}$ bairro apresenta uma área de Mata Atlântica que recobre a montanha e se estende, em determinados locais, até o litoral. Os cães foram coletados de duas áreas distintas:

- Área A: delimitada pelas coordenadas $23^{\circ}$ 03 906' S - 430 34 065' W (7m), 23o 04 021' S 43o 33 968' W (70m) e 23o 03 904' S - 43o 33 583' W (170m), com áreas não muito desmatadas e casas construídas de formas espaçadas.

- Área B: delimitada pelas coordenadas $23^{\circ}$ 03 713' S - 43o 33 901' W (63m), 23o 03 644' S 43o 33 647' W (70m) e 23o 03 763' S - 43o 33 692' W (105m), casas construídas muito próximas uma das outras e mata degradada.

Em ambas as áreas, haviam casas localizadas dentro da mata, sendo que na área $\mathrm{A}$, as casas atingiam até $50 \mathrm{~m}$ de distância da mata e na área $\mathrm{B}$ até $700 \mathrm{~m}$.

\section{População canina}

A seleção do grupo de estudo foi feita utilizando a técnica de IFA em 120 cães, quando se diagnosticou 25 animais soropositivos, a partir daí, um grupo de 55 animais foi escolhido para acompanhamento bimensal, sendo 35 soronegativos e 20 soropositivos, com idades aleatórias. As amostras de sangue dos cães para obtenção do soro foram coletadas por punção da veia cefálica, com autorização dos proprietários, no período de julho de 2001 a setembro de 2002. Soro de dez cães de área não-endêmica do Rio de Janeiro foram coletados da mesma forma.

\section{IFA}

Os antígenos utilizados foram de formas promastigotas de L. chagasi (cepa L-579), obtidos de cultura axênica de NNN + LIT, na fase exponencial. Foi usado o conjugado fluoresceinado IgG anti-cão (Sigma, Saint Louis, Missouri, Estados Unidos) 5. Os soros foram testados nas diluições $1 / 10$ a $1 / 2.560$ e adotado como critério de soropositividade, cães com título igual ou superior a 1/40 como estabelecido pelo Ministério da Saúde.

\section{Western blot}

Os antígenos foram obtidos de formas promastigotas de L. chagasi (cepa L579) vinda de cultura contendo "Schneider's complete medium" (Sigma, Saint Louis, Missouri, Estados Unidos) e $10,0 \%$ soro fetal bovino, na fase exponencial 4 .

\section{Necrópsia}

Cinco do vinte animais soropositivos ficaram doentes durante o acompanhamento, um morreu e quatro foram então eutanasiados com overdose de ketamina $(50 \mathrm{mg} / \mathrm{kg}$, IV) e cloreto de potássio (100mg/kg, IV). Após a necrópsia, foram feitos "imprints" de pele, baço, fígado, coração, pulmão, rim, líquido ascítico e linfonodos, que posteriormente foram corados com Giemsa e examinados para observar presença de formas amastigotas.

\section{Resultados}

\section{IFA}

A soroprevalência canina em Barra de Guaratiba após 12 meses de estudo, foi de 25,0\% (30/ 120), incluindo os animais que soroconverteram no decorrer do acompanhamento. Nos animais acompanhados, foram observados cinco perfis: (a) cães que permaneceram sorologica- 
mente negativos (30/55); (b) os que soroconverteram (5/25) no período de 2 a 8 meses, $4 / 5$ desses cães tinham menos de três anos de idade e $100,0 \%$ desses animais moravam dentro ou até $30 \mathrm{~m}$ de distância da mata $(5 / 5)$; (c) soropositivos, com títulos entre $1 / 40$ e 1/80, que mantiveram esses títulos durante o acompanhamento (11/25); (d) soropositivos com títulos entre $1 / 40$ e 1/80, que após alguns meses seus títulos aumentaram significativamente (6/25); (e) e aqueles que desde o início do acompanhamento apresentaram altos títulos, permanecendo constante (3/25). Os dez cães de área não endêmica foram negativos para o IFA.

\section{Western blot}

As frações antigênicas imunodominantes de $23,5,25,29,32,42,5 \mathrm{kDa}$ foram fortemente reconhecidas pelos soros de cães positivos pelo IFA. O peptídeo de $68,5 \mathrm{kDa}$ foi reconhecido somente pelos cães soropositivos (5/55) que ficaram doentes durante o acompanhamento e até oito meses antes de apresentarem sintomatologia. Não houve diferença no perfil de reconhecimento antigênico de cães soronegativos de área endêmica e de área não endêmica, reconhecendo fracamente frações peptídicas de 37, 42,5 e 71,5kDa. Dentre os 35 cães soronegativos pelo IFA, nove reconheceram os antígenos de 29 e $32 \mathrm{kDa}$ no início do acompanhamento, e após alguns meses cinco desses animais soroconverteram pelo IFA.

\section{Necrópsia}

Dos cinco cães que ficaram doentes, $3 / 5$ desses animais tinham menos de três anos de idade e todos tinham títulos superiores à $1 / 160$ pelo IFA. As formas amastigotas foram encontradas em todos os materiais de "imprint" e observouse que quanto maior o título sorológico, maior também era a quantidade de amastigotas observada.

\section{Discussão}

Em Barra de Guaratiba, observamos que no período de 2001 a 2002 além de uma alta prevalência $(25,0 \%)$ de cães infectados pela LVA, também está ocorrendo a transmissão ativa da doença, visto que durante o mesmo período foi detectado um caso humano (resultado não mostrado) e, no grupo de animais infectados, 20,0\% soroconverteram pelo teste de IFA. Estes resultados demonstram que apesar das campanhas implementadas pela FUNASA, não se tem avan- çado muito no que se refere ao controle da LVA mesmo em áreas urbanas e periurbanas do Estado do Rio de Janeiro, que são de fácil acesso.

O diagnóstico dos cães baseado na técnica de IFA aliado a outros fatores tais como, inquéritos sorológicos irregulares e a falta de treinamento das equipes que as executam, talvez também tenham possibilitado a permanência na área de animais susceptíveis.

Em nosso estudo observamos que o período de soroconversão dos cães variou de 2 a 8 meses, estes resultados ressaltam a necessidade da execução dos inquéritos sorológicos pelo menos bimensais, que visem o diagnóstico rápido da doença. Dos cinco cães que soroconverteram, quatro tinham menos de três anos de idade, demonstrando uma maior susceptibilidade dos animais mais jovens.

A proximidade da mata mostrou uma correlação direta com a incidência de casos caninos, já que $100,0 \%$ dos animais que soroconverteram moravam nestes locais, como também $84,0 \%$ dos animais soropositivos. Perto da mata, também houve uma maior freqüência na coleta de vetores (dados não apresentados). Cabrera et al. 6 também demonstraram uma alta prevalência (29,0\%) de gambás (Didelphis marsupialis) infectados pela LVA nessa área, sendo que a presença destes animais no peridomicílio aumentava o risco da infecção canina em 2,6 vezes. Estas observações aliadas aos nossos resultados, sugerem que a presença do gambá, que pode estar atuando como um elo entre os ciclos domésticos e silvestres e a alta freqüência dos vetores propiciam um maior número de cães soropositivos próximos à mata.

Os perfis sorológicos dos cães submetidos ao teste de IFA mostraram que entre os cães há um espectro de resposta imunológica semelhante ao que ocorre no homem, composto pelas seguintes características: (a) cães que permanecem não reativos por longos períodos a despeito da proximidade com cães soropositivos; (b) cães que permanecem com títulos baixos $(\leq 1: 80)$, possivelmente controlando a infecção; (c) cães que no início têm títulos baixos e após algum tempo passam a apresentar títulos altos ( $\geq 1: 160)$, em geral permanecendo assintomáticos, mas eventualmente passando a apresentar alguma sintomatologia. Pode-se considerar que os animais com altos títulos sorológicos e também sintomáticos, que se enquadram no perfil (c), são aqueles com maior potencial de serem fontes de infecção para os flebótomos, visto que em muitos casos, além de um parasitismo disseminado em vários órgãos, também possuíam uma alta carga parasitária na pele. Por outro lado, animais assinto- 
máticos também são capazes de servir como fonte de infecção para flebótomos e apesar de serem capazes de infectar um número menor de insetos, em geral é a maioria em uma população.

Com relação ao estudo do reconhecimento antigênico feito através da técnica de WB, nossos resultados confirmam a sua maior sensibilidade em comparação ao IFA, visto que aproximadamente $26,0 \%$ dos cães que estavam negativos para o teste de IFA já reconheciam as frações antigênicas (29 e 32kDa) até oito meses antes da soroconversão sendo que alguns permaneceram negativos até o fim do acompanhamento. Provavelmente os cães positivos para o WB e negativos para o IFA, sejam animais resistentes que apresentam baixos níveis de anticorpos não detectáveis pelo IFA.

O reconhecimento dos peptídeos de 29 e $32 \mathrm{kDa}$ apresenta uma correlação direta com pa-

\section{Resumo}

Em Barra de Guaratiba, área endêmica de leishmaniose visceral americana (LVA) no Rio de Janeiro, Brasil, as campanhas de controle não têm sido capazes de reduzir a infecção canina. Este fato nos levou a aprofundar o estudo do cão como reservatório da Leishmania chagasi em ambiente periurbano, através de acompanhamento clínico e sorológico usando as técnicas de IFA e WB. O reconhecimento dos peptideos de 29 e $32 \mathrm{kDa}$ por soro de cães comprovadamente infectados por L. chagasi foi observado. Além disso, somente soros de cães sintomáticos reconheceram o antígeno de $68,5 \mathrm{kDa}$, podendo esse peptídeo ser recomendado como parâmetro para eliminação dos cães em área endêmica. A técnica de WB provou ser mais sensível que IFA, desde que as frações peptídicas de 29 e 32kDa foram reconhecidas por soro de cães soronegativos para LVA, até 8 meses antes da soroconversão pelo IFA. A proximidade da mata foi fator relevante para aumentar o risco de infecção por L. chagasi nos cães, possivelmente devido à presença de reservatórios silvestres.

Leishmaniose Visceral; Cães; Imunofluorescência; Western Blot rasitismo tissular, já que todos os soros de animais com parasitas nos tecidos reconheceram estes antígenos, podendo esses peptídeos ser utilizados como preditores de infecção ${ }^{3}$. Nos nossos resultados, observamos que somente os soros de cães sintomáticos reconheceram precocemente a banda de $68,5 \mathrm{kDa}$, indicando a possibilidade do uso deste antígeno como preditor de doença.

O presente trabalho ressalta a necessidade de se implementar medidas de controle da LVA levando-se em conta as diferenças microambientais de cada região e sugere que o uso da técnica de WB seria o mais adequado no diagnóstico da LV canina, permitindo a detecção precoce dos animais infectados e também identificando dentro da população canina aqueles que possivelmente desenvolverão a doença, sendo estes as principais fontes de infecção para os flebótomos.

\section{Colaboradores}

A. V. M. Silva redigiu o artigo e participou da execução da técnica de Western blot e IFA, do trabalho de campo, da coleta e caracterização dos flebótomos e das discussões científicas. A. A. de Paula participou da execução da técnica de Western blot. M. A. A. Cabrera participou da execução da técnica de IFA. J. C. A. Carreira participou do trabalho de campo, da coleta e caracterização dos flebótomos e das discussões científicas e contribuiu com a redação do artigo. 


\section{Referências}

1. Nicolle C, Comte C. Origine du Kala azar. CRL' Acad Sci 1908; 146:789.

2. Deane LM, Deane MP. Observações preliminares sobre a importância comparativa do homem, do cão e da raposa Lycalopex vetulus como reservatórios da $L$. donovani em área endêmica de calazar no Ceará. Hospital 1955; 48:61-70.

3. De Paula AA, Da Silva AVM, Fernandes O, Jansen AM. The use of immunoblot analysis in the diagnosis of canine visceral leishmaniasis in an endemic area of Rio de Janeiro. J Parasitol 2003; 89 Suppl 4:832-6.

4. Aisa MJ, Castillejo S, Gallego M, Fisa R, Riera MC, De Colmenares M, et al. Diagnostic potential of western blot analysis of sera from dogs with leishmaniasis in endemic areas and significance of the pattern. Am J Trop Med Hyg 1998; 58:154-9.
5. Camargo ME. Fluorescent antibody test for the serodiagnosis of American Trypanosomiasis.Technical modification employing preserved cultured forms of Trypanosoma cruzi in a slide test. Rev Inst Med Trop São Paulo 1966; 8:227-34.

6. Cabrera MAA, De Paula AA, Camacho LAB, Marzochi CA, Aguiar GM, Xavier SC, et al. Canine Visceral Leishmaniasis in Barra de Guaratiba, Rio de Janeiro, Brazil: assessment of some risk factors. Rev Inst Med Trop São Paulo 2003; 45 Suppl 2:79-83.

Recebido em 03/Mai/2004

Versão final reapresentada em 14/Set/2004 Aprovado em 16/Set/2004 